Article

\title{
Effects of Y, GdCu, and Al Addition on the Thermoelectric Behavior of CoCrFeNi High Entropy Alloys
}

\author{
Wanqing Dong ${ }^{1}$, Zheng Zhou ${ }^{1}$, Lijun Zhang ${ }^{1}$, Mengdi Zhang ${ }^{1}$, Peter K. Liaw ${ }^{2} \mathbb{D}$, \\ Gong $\mathrm{Li}^{1, *}$ and Riping Liu ${ }^{1}$ \\ 1 State Key Laboratory of Metastable Materials Science and Technology, Yanshan University, \\ Qinhuangdao 066004, China; dongwanqing@stumail.ysu.edu.cn (W.D.); \\ zhouzheng@stumail.ysu.edu.cn (Z.Z.); zhanglijun@stumail.ysu.edu.cn (L.Z.); \\ mdmdmd@stumail.ysu.edu.cn (M.Z.); riping@ysu.edu.cn (R.L.) \\ 2 Department of Materials Science and Engineering, The University of Tennessee, Knoxville, \\ TN 37996-2200, USA; pliaw@utk.edu \\ * Correspondence: gongli@ysu.edu.cn; Tel.: +86-137-8593-1860
}

Received: 13 September 2018; Accepted: 27 September 2018; Published: 29 September 2018

check for updates

\begin{abstract}
Thermoelectric (TE) materials can interconvert waste heat into electricity, which will become alternative energy sources in the future. The high-entropy alloys (HEAs) as a new class of materials are well-known for some excellent properties, such as high friction toughness, excellent fatigue resistance, and corrosion resistance. Here, we present a series of HEAs to be potential candidates for the thermoelectric materials. The thermoelectric properties of $\mathrm{Y}_{x} \mathrm{CoCrFeNi}, \mathrm{Gd}_{x} \mathrm{CoCrFeNiCu}$, and annealed $\mathrm{Al}_{0.3} \mathrm{CoCrFeNi}$ were investigated. The effects of grain size and formation of the second phase on thermoelectric properties were revealed. In HEAs, we can reduce the thermal conductivity by controlling the phonon scattering due to the considerable complexity of the alloys. The Y, Gd-doped HEAs are competitive candidate thermoelectric materials for energy conversion in the future.
\end{abstract}

Keywords: high-entropy alloys; thermoelectric; heat treatment

\section{Introduction}

Traditional alloys include one or two principal elements, but high entropy alloys (HEAs) were defined by Yeh et al. as a new class of materials containing five or more principal elements, each with concentrations between 5 atomic percent (at \%) and 35 atomic percent (at \%) [1-3]. Studies have shown that HEAs exhibit some excellent properties, compared with conventional alloys, such as high hardness, great resistance to evaluation wear, corrosion, friction, fatigue, and oxidation [3-15].

With the development of the social economy and technology, the energy consumption of the world has increased significantly, and the traditional petrochemical energy has been increasingly exhausted. At present, more than 60 percent of energy is lost in the form of heat during the use of energy [16]. Thermoelectric (TE) materials are going to be the potential candidates for alternative sources of energy, because heat can be directly converted into the electrical energy and vice versa $[17,18]$. Therefore, the TE materials are also attractive because they can contribute to realizing the sustainable utilization of resources [19]. If the industrial waste heat, automobile exhaust waste heat and other waste heat are converted through thermoelectric materials, the energy efficiency will be greatly improved, and the energy crisis and environment pollution will be alleviated. The thermoelectric material is a kind of functional material which utilizes the transport and interaction of carriers and phonons in solids to achieve the direct conversion between the thermal energy and electrical energy. 
The thermoelectric-power generation or refrigeration device made of thermoelectric material has the advantages of being noise free, zero emission and pollution free, lacking vibration, small volume, etc. It has been applied in deep space exploration and refrigeration, and has great potential in waste heat power generation $[20,21]$.

Conventional thermoelectric materials currently in use include $\mathrm{Bi}_{2} \mathrm{Te}_{3}$ based, $\mathrm{PbTe}$ based and $\mathrm{SiGe}$ based, etc. $\mathrm{Bi}_{2} \mathrm{Te}_{3}$ is currently the most commercially successful thermoelectric material near room temperature. It is widely used in the field of the thermoelectric refrigeration, and is also the thermoelectric material with the highest power generation efficiency at low temperature [22]. Although $\mathrm{Bi}_{2} \mathrm{Te}_{3}$ has been commercialized, its performance can be further improved by doping, composition adjustment, etc. $\mathrm{PbTe}$ is the medium temperature thermoelectric material that has been studied for the longest time and PbTe-based materials have been successfully used in the NASA aerospace missions many times since 1960. In recent years, PbTe-based thermoelectric materials have made great progress. The application temperature range of the Si-Ge alloy is more than $1000 \mathrm{~K}$. It has been successfully applied to some deep space detectors. For example, in the radioisotope temperature difference battery of the Cassini Saturn detector, the thermoelectric conversion device is prepared by the Si-Ge alloy. However, the reserves of $\mathrm{Te}$ and $\mathrm{Ge}$ elements are scarce and very costly; $\mathrm{Pb}$ is toxic, pollutes the environment, and endangers people's health. Therefore, the development of environmentally friendly, new low-cost thermoelectric materials is particularly urgent.

HEAs are always being studied for their mechanical properties. Maybe many new and unexpected properties remain for us to explore. In the search for TE materials, the performance of this kind of material is estimated by the dimensionless figure of merit, defined as $Z T=S^{2} T \sigma / k$ [23], where $S$ is the Seebeck coefficient, $T$ is the absolute temperature, $\sigma$ is the electrical conductivity, and $k=k_{e}+k_{l}$ is the total thermal conductivity, where $k_{e}$ and $k_{l}$ are the electronic and lattice components of the thermal conductivity, respectively. In practical applications, the efficiency of the TE material depends on the average $\mathrm{ZT}$ over the whole working temperature range, rather than its max ZT [24]. So it is our goal to raise the average $\mathrm{ZT}$ over the entire working temperature. The larger the $\mathrm{ZT}$ value, the better the performance of the TE material. We can easily understand from the equation of ZT that large $S$ and $\sigma$, and low $k$ will attain a satisfactory ZT value [25]. In addition, the Seebeck coefficient, electric conductivity, and thermal conductivity, which measure the performance of TE materials, are coupled by the carrier concentration [26]. The variation trend of the three parameters was summarized in Figure 1 as a result of the great efforts of the researchers [27]. We observe that different carrier concentrations lead to various conduction properties. The materials can be divided into insulators, semiconductors, and metals according to their carrier concentration. With the increase of the carrier concentration, the Seebeck coefficient significantly decreases, while the electric conductivity and the electronic thermal conductivity increase [28]. At present, semiconductor materials are the hotspot of the thermoelectric properties, and the TE properties of metallic materials are still remain to be studied.

Generally, for a TE material, the reduction of the $k_{l}$ is an effective measure to obtain a high ZT value. And $k_{e}$ relates to the conductivity of the materials, whereas $k_{l}$ has nothing to do with other parameters. The scattering of phonons plays a crucial part on $k_{l}$. The complexity, or disorder in the crystal structure leads to the scattering of phonons. So, it is a feasible method to reduce the lattice thermal conductivity by enhancing the phonon scattering [29-33].

In HEAs, Yeh summarized mainly four core effects of this new kind of alloys. One of them is the severe lattice-distortion effect $[1,3,14]$. The severe lattice-distortion effect is always compared with the traditional alloys, where the lattice site is mainly occupied by the principal element. For HEAs, each constituent element has the same possibility to occupy the lattice sites, since the size of each atom can be different in some cases, which can lead to severe lattice distortion $[1,3,15]$. Therefore, in the HEAs, the strategies to control phonon scattering can be generally achieved through the complex nature of the materials [34]. Because of the severe lattice-distortion effect and the points defect, HEAs offer a large amount of complexity, which is conducive to phonon scattering. The phase structure of the 
HEAs is always highly symmetrical, such as face-centered-cubic (FCC), body-centered-cubic (BCC), and hexagonal-close-packed (HCP) phases. So it is possible for the new class of materials to reach a high convergence of the bands close to the Fermi level to attain the high Seebeck coefficient values [35-37]. Therefore, the peculiar microstructures and properties of the HEA provide opportunities to obtain the low lattice thermal conductivity and appropriate Seebeck coefficient to achieve a high ZT value and act as a new class of thermoelectric materials.

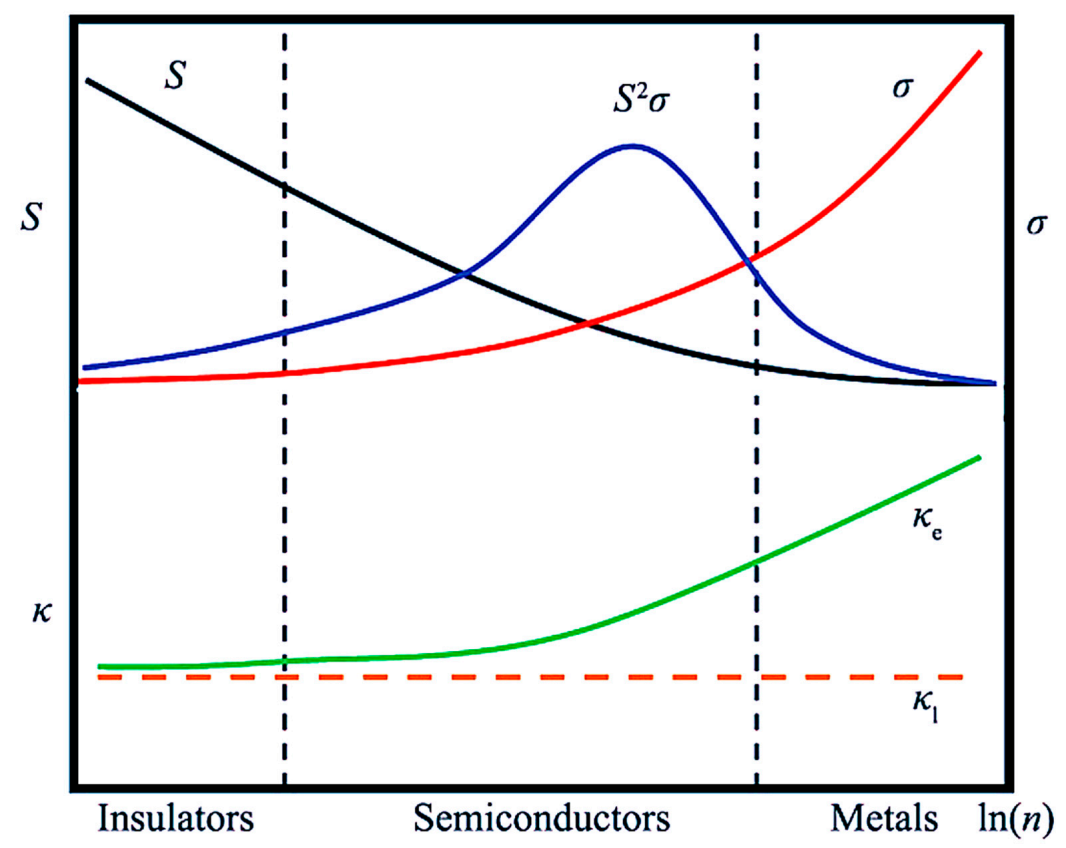

Figure 1. Correlation of thermoelectric parameters and carrier concentrations.

Nevertheless, the thermoelectric properties of the HEAs were not extensively studied in the literature. Here the annealed $\mathrm{Al}_{0.3} \mathrm{CoCrFeNi}$ (annealed at $473 \mathrm{~K}, 673 \mathrm{~K}, 873 \mathrm{~K}$, and $1073 \mathrm{~K}$ ), $\mathrm{Gd}_{x} \mathrm{CoCrFeNiCu}(x=0,0.3)$, and $\mathrm{Y}_{x} \mathrm{CoCrFeNiCu}(x=0,0.05,0.1)$ were prepared, and the parameters for the thermoelectric properties were studied in this paper.

\section{Experimental Section}

The button ingots ( $30 \mathrm{~g}$ each) of the sample were prepared by the arc-melting method in a vacuum-titanium-gettered high purity argon (99.999 volume percent, vol \%) atmosphere and cooled by the water in a copper crucible. The purity of the element was greater than 99.95 weight percent ( $\mathrm{wt} \%$ ). The samples were flipped and remelted at least five times in order to achieve a good homogeneity. We obtain $\mathrm{Al}_{0.3} \mathrm{CoCrFeNi}, \mathrm{Gd}_{x} \mathrm{CoCrFeNiCu}(x=0,0.3)$, and $\mathrm{Y}_{x} \mathrm{CoCrFeNi}(x=0,0.05,0.1)$ ingots. The $\mathrm{Al}_{0.3} \mathrm{CoCrFeNi}$ was then annealed at $473 \mathrm{~K}, 673 \mathrm{~K}, 873 \mathrm{~K}$, and $1073 \mathrm{~K}$ in the muffle furnace, respectively. The as-cast samples were cut and then polished to obtain a bright and smooth surface. The crystalline structures of all the samples were obtained with X-ray diffraction (XRD) (Rigaku, Tokyo, Japan) using the $\mathrm{Cu}-\mathrm{K} \alpha$ radiation, operating in the $2 \theta$ range of $20^{\circ}-100^{\circ}$ at a scanning rate of $4^{\circ} / \mathrm{min}$. The microstructures of the samples were characterized by a SE-4800 scanning electron microscope (SEM) (Hitachi, Tokyo, Japan) operated in a back-scatter electron (BSE) mode. The thermal conductivity of the samples was measured in the laser thermal conductivity analyzer (TC-9000H, Ulvac-Riko, Yokohama, Japan), and the cylindrical samples were cut from the center of the ingots with a diameter of $6 \mathrm{~mm}$ and thickness of $1 \mathrm{~mm}$. A Seebeck coefficient analyzer (ZEM-3) (Advance-Riko, Yokohama, Japan) was used to determine the temperature-dependent Seebeck coefficient and the electrical resistivity $(1 / \sigma)$. All of the samples were studied from $298 \mathrm{~K}$ to $\sim 873 \mathrm{~K}$. The temperature difference of each measure point was $50 \mathrm{~K}$. 


\section{Results}

\subsection{Crystal Structure}

The XRD patterns of the annealed $\mathrm{Al}_{0.3} \mathrm{CoCrFeNi}$ were shown in Figure 2. The $\mathrm{Al}_{0.3} \mathrm{CoCrFeNi}$ alloy exhibited a simple FCC crystal structure at all the mentioned annealing temperatures. Figures $3 a$ and 4 a show the XRD patterns of $\mathrm{Gd}_{x} \mathrm{CoCrFeNiCu}$ and $\mathrm{Y}_{x} \mathrm{CoCrFeNi}$, respectively. Only the FCC phase was detected when $x=0$. With the increases of $Y$ and $\mathrm{Gd}$ contents, new peaks appeared. Those new diffraction peaks were identified as the Laves phase. The microstructure of these HEAs was also displayed in the Figures $3 b, c$ and $4 b, c$. The HEAs with the $Y$ addition show the typical cast dendrite (DR) identified as the FCC phase, and interdendrite (IR) identified as the Laves phase. With the increase of the $\mathrm{Y}$ content, the grain is refined. Based on the XRD patterns of $\mathrm{Gd}_{x} \mathrm{CoCrFeNiCu}$, it can be concluded that when $x=0$, the diffraction peaks coincide with the FCC phase. In the sample with $x=0.3$, both FCC and Laves phases can be observed, while the FCC structure is still the main phase. With the increase of the Gd content, the grain is refined.

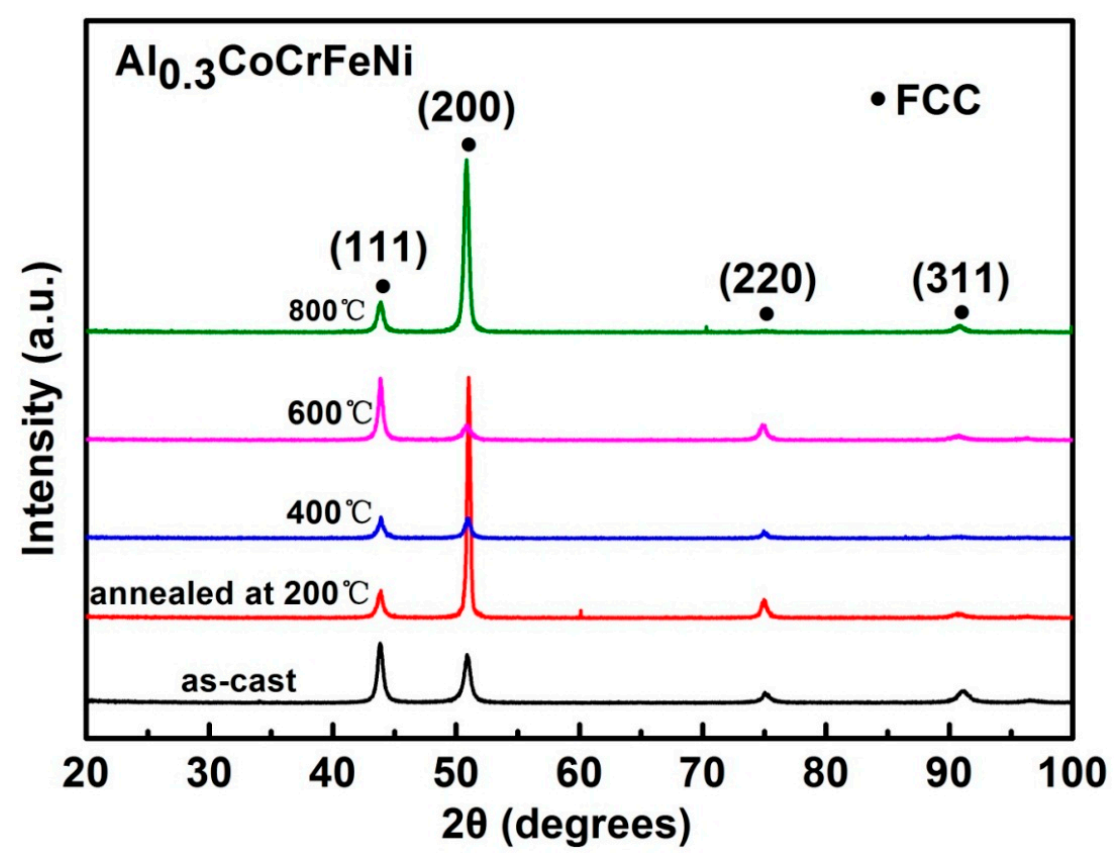

Figure 2. X-ray diffraction (XRD) patterns of the annealed $\mathrm{Al}_{0.3} \mathrm{CoCrFeNi}$. 


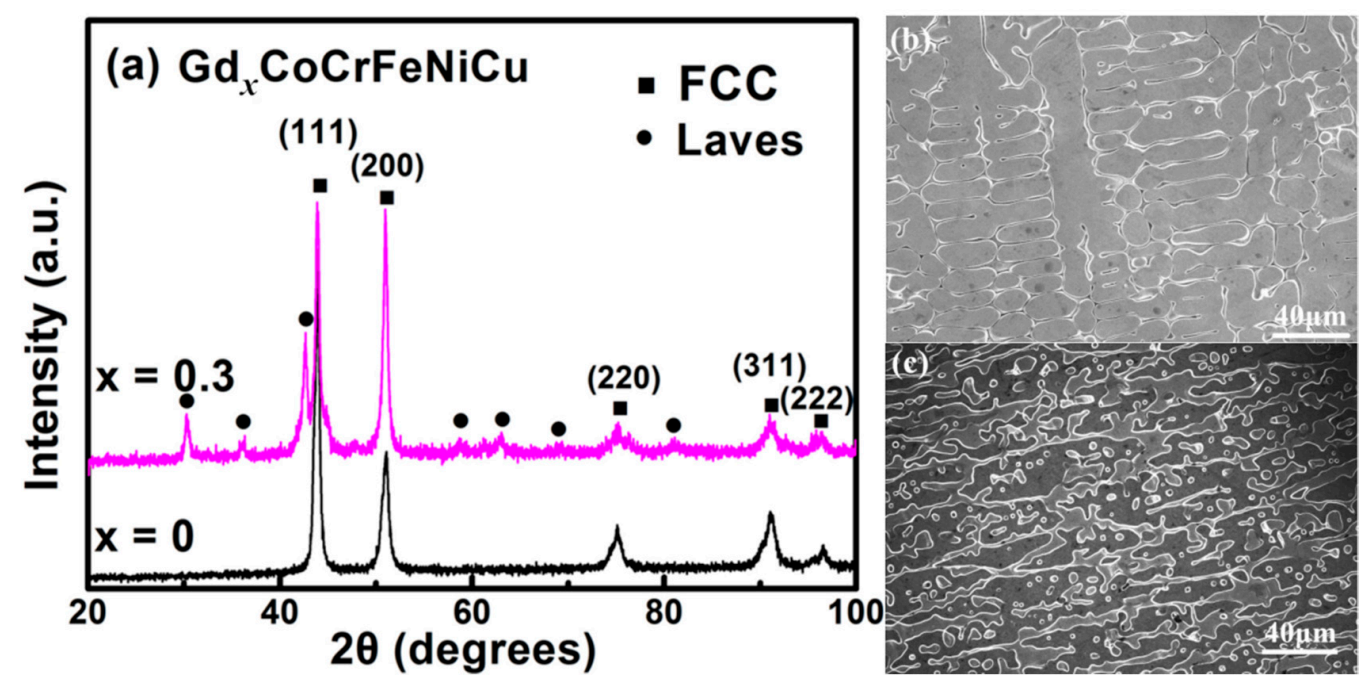

Figure 3. (a) XRD patterns of the $\mathrm{Gd}_{x} \mathrm{CoCrFeNiCu}$; (b) Scanning electron microscope (SEM) microstructures of $\mathrm{CoCrFeNiCu}$; (c) $\mathrm{SEM}$ microstructures of $\mathrm{Gd}_{0.3} \mathrm{CoCrFeNiCu}$.
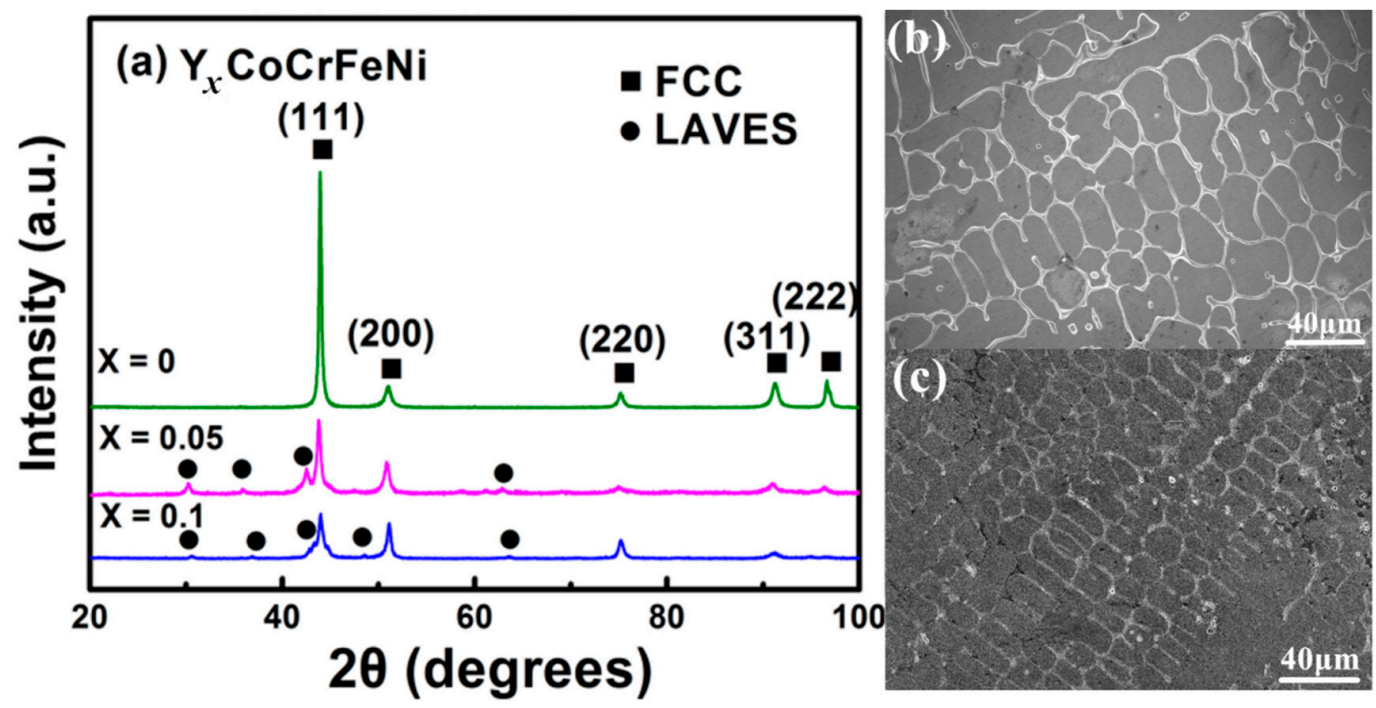

Figure 4. (a) XRD patterns of the $\mathrm{Y}_{x} \mathrm{CoCrFeNi}$; (b) SEM microstructures of $\mathrm{Y}_{0.05} \mathrm{CoCrFeNi}$; (c) SEM microstructures of $\mathrm{Y}_{0.1} \mathrm{CoCrFeNi}$.

\subsection{Electrical Conductivity}

The average electrical conductivity for the annealed $\mathrm{Al}_{0.3} \mathrm{CoCrFeNi}$ alloys was presented in Figure 5a. Electrical conductivity is closely connected with the change of temperature. In general, the electrical conductivity of the alloys decreases with increasing the temperature, while the electrical conductivity of the semiconductor is directly proportional to the temperature within a certain temperature range [8-11]. We observed from Figure 5 a that the $\mathrm{Al}_{0.3}$-HEA worked in accordance with the trend, and the electrical conductivity was inversely proportional to the temperature [14]. But they do not exactly line up with the trend of the annealing temperature. For the sample as-cast, annealed at $473 \mathrm{~K}$ and $873 \mathrm{~K}$, the electrical conductivity decreases with the increasing the annealing temperature, while the other two samples do not entirely follow this rule. It is noted that the sample annealed at $673 \mathrm{~K}$ shows the highest electrical conductivity among all of the mentioned $\mathrm{Al}_{0.3}$-HEAs. The conductivity of the samples annealed at $1073 \mathrm{~K}$ falls in between the as-cast and annealed at $473 \mathrm{~K}$ samples. The conductivity of $\mathrm{Gd}_{x} \mathrm{CoCrFeNiCu}$ and $\mathrm{Y}_{x} \mathrm{CoCrFeNi}$ were shown in Figures 6a and 7a. The electrical conductivity decreases with the increase of $\mathrm{Y}$ and $\mathrm{Gd}$. The $\mathrm{Gd}_{0} \mathrm{CoCrFeNiCu}$ shows the highest conductivity among all tested samples. 

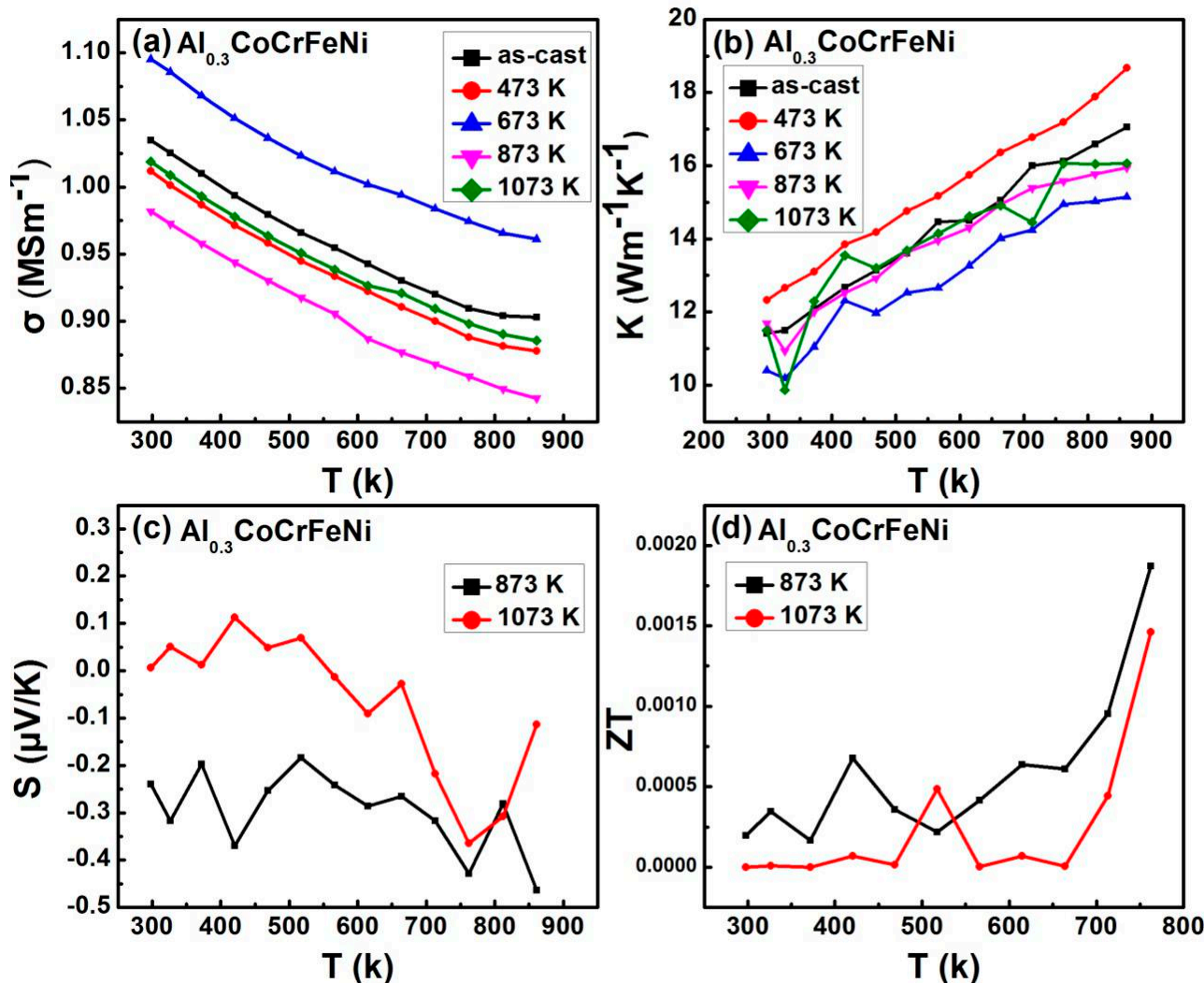

Figure 5. Thermoelectric properties of the annealed $\mathrm{Al}_{0.3} \mathrm{CoCrFeNi}$ alloy. (a) Electrical conductivity; (b) Thermal conductivity; (c) Seebeck coefficient; (d) Figure of merit, ZT.
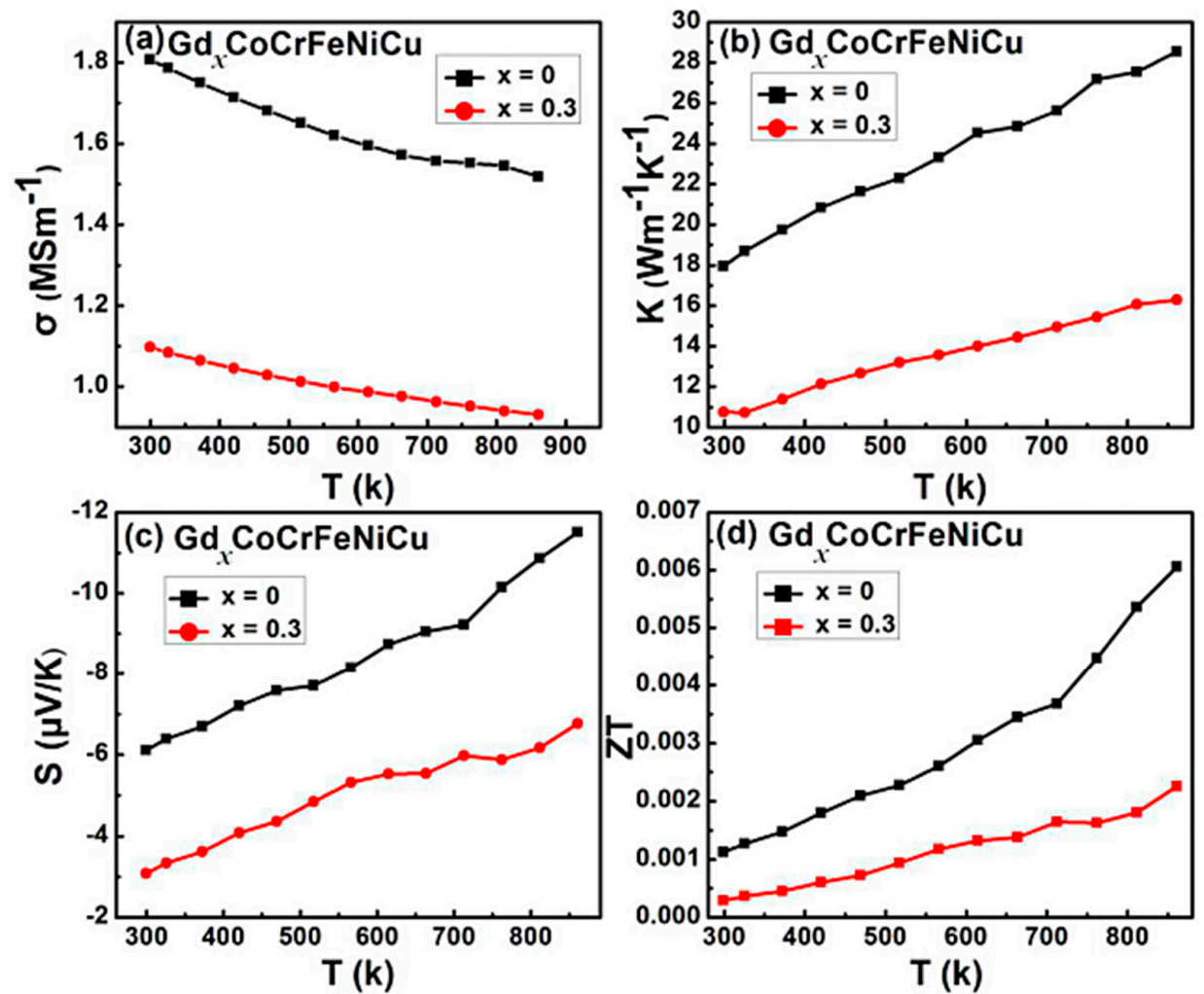

Figure 6. Thermoelectric properties of the $\mathrm{Gd}_{x} \mathrm{CoCrFeNiCu}$ alloy. (a) Electrical conductivity; (b) Thermal conductivity; (c) Seebeck coefficient; (d) Figure of merit, ZT. 

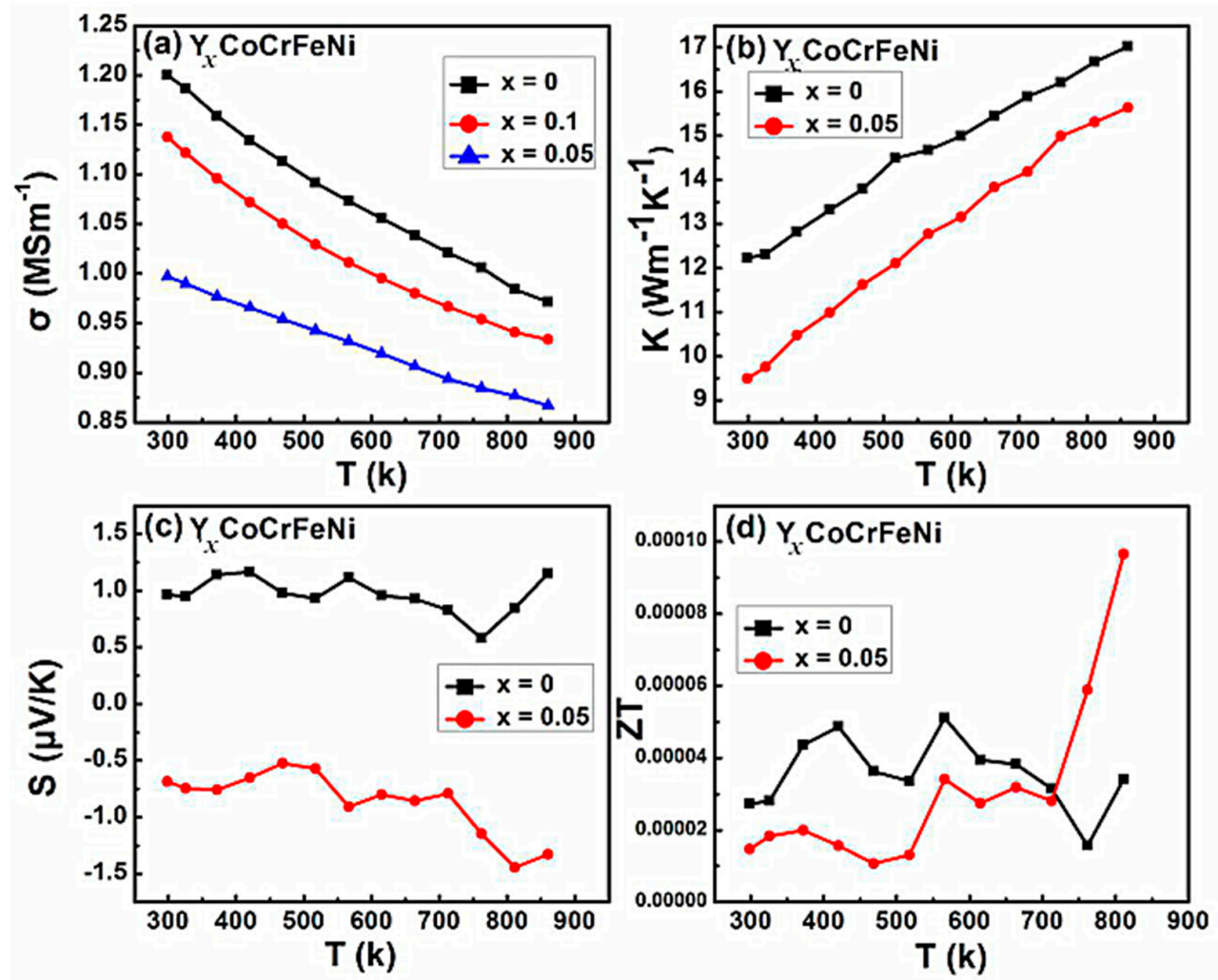

Figure 7. Thermoelectric properties of the $\mathrm{Y}_{x} \mathrm{CoCrFeNi}$ alloy. (a) Electrical conductivity; (b) Thermal conductivity; (c) Seebeck coefficient; (d) Figure of merit, ZT.

\subsection{Thermal Conductivity}

The thermal conductivity $(\mathrm{k})$ of $\mathrm{Al}_{0.3} \mathrm{CoCrFeNi}$ was shown in Figure $5 \mathrm{~b}$. Thermal conductivity was measured between $298 \mathrm{~K}$ and $873 \mathrm{~K}$. The samples were tested every $323 \mathrm{~K}$. In general, the thermal conductivity of $\mathrm{Al}_{0.3}$ HEAs was in direct proportion to the temperature except for some special points. The conductivity of $\mathrm{Gd}_{x} \mathrm{CoCrFeNiCu}$ and $\mathrm{Y}_{x} \mathrm{CoCrFeNi}$ also increases with increasing temperature. Furthermore, it was observed that the $k$ value decreases as the contents of $Y$ and $G d$ increase. The $\mathrm{Y}_{0.05} \mathrm{CoCrFeNi}$ was noted for its lowest thermal conductivity in all the samples studied.

\subsection{Seebeck Coefficient}

The average Seebeck coefficient values for $\mathrm{Al}_{0.3} \mathrm{CoCrFeNi}$ were exhibited in Figure $5 \mathrm{c}$. It was observed that the alloys annealed at $673 \mathrm{~K}$ and $1073 \mathrm{~K}$ reveal a negative Seebeck coefficient. The positive and negative values of the Seebeck coefficient represent the different diffusion patterns of electrons. For the $\mathrm{Al}_{0.3}$-HEAs, the absolute values of the Seebeck coefficient almost decrease with increasing the annealing temperature, except for some points. The change of $\mathrm{S}$ did not show an obvious relationship with the test temperature. The Seebeck coefficient of the other two HEAs were shown in Figures $6 \mathrm{c}$ and $7 \mathrm{c}$. The absolute values, $\mathrm{S}$, of the $\mathrm{Gd}_{x} \mathrm{CoCrFeNiCu}$ alloys decrease with the increase of the Gd content. Nevertheless, the $\mathrm{S}$ is in the direct proportion to the test temperature. The absolute Seebeck coefficient values for $Y_{x}$-HEAs decrease with increasing $x$ in the low-temperature range $(298 \mathrm{~K}$ to $573 \mathrm{~K}$ ). In the temperature range of $573 \mathrm{~K}$ to $723 \mathrm{~K}, \mathrm{~S}_{0.05}$ was greater than $\mathrm{S}_{0.1}$, and in the range of $773 \mathrm{~K}$ to $873 \mathrm{~K}, \mathrm{Y}_{0.05}$ shows the highest absolute Seebeck coefficient.

\section{Discussion}

Recently, particular interest has focused on the formation of the secondary phase in thermoelectric materials to reduce their lattice electric conductivity [31]. From the XRD patterns of the as-cast $\mathrm{Y}_{x} \mathrm{CoCrFeNi}$, the connection between crystal structures and $\mathrm{Y}$ contents can be clearly observed. 
Only diffraction peaks corresponding to the FCC crystal structure was observed in the $\mathrm{Y}_{0} \mathrm{CoCrFeNi}$ alloy. However, reflections of the Laves phases can be found with the increase of the $\mathrm{Y}$ content. The Laves phase can be identified as a YNi type. With the increase of the $Y$ content, the grain is refined. The microstructure of $\mathrm{Gd}_{X} \mathrm{CoCrFeNiCu}$ was shown in the Figure $3 b, c$, which was typical of dendritic structures. The grain size decreases with changing $x$ from 0 to 0.3 . In the multiphase compounds, the inhomogeneous distribution of dopants between the matrix and secondary phase plays a crucial role in the electronic-transport properties [23]. The XRD patterns and microstructures were observed in Figure 2. All of the $\mathrm{Al}_{0.3}$-HEA samples exhibit a simple FCC structure, and with the increase of the annealing temperature, the grain size increases [38]. We can regard all of the HEA samples as similar low-dimensional thermoelectric materials, which follows the size effect. The low-dimensional thermoelectric material reduces the average free path of the phonon by the size effect to decrease the lattice thermal conductivity [29,39-43]. The lattice thermal conductivity decreases with the decrease of the grain size, which is due to the fact that the small grain size will enhance the long wave phonons scattering. The grain size and thermal conductivity of all samples conform to this rule [12-15].

From the electric-conductivity data, we observe that the conductivity of all the HEA samples decreases with increasing temperature, which is consistent with the traditional alloys. The $\mathrm{Al}_{0.3} \mathrm{HEAs}$, annealed at $673 \mathrm{~K}$, possess a high electric conductivity $\left(\sim 1.1 \mathrm{MS} \cdot \mathrm{m}^{-1}\right)$. The connection between the electric conductivity and annealing temperature was, however, not entirely systematic. Furthermore, a small variation in the composition of the main phase will consequently affect the value for the electric conductivity [36]. With increasing the contents of $\mathrm{Y}$ and $\mathrm{Gd}$, the $\mathrm{K}$ value decreases. It is because the movement of the carriers (electrons in the metal) is affected by the generation of the Laves phase, leading to the decrease of the electric conductivity.

The change in the Seebeck coefficient for the $\mathrm{Al}_{0.3}$-HEAs was not entirely systematic over the full annealing temperature range, but the $S$ was changing in a systematic order during the high annealing temperature ( $873 \mathrm{~K}$ and $1073 \mathrm{~K})$. The absolute $\mathrm{S}$ value decreases as the annealing temperature changes from $873 \mathrm{~K}$ to $1073 \mathrm{~K}$, and the coefficient was nearly in a direct proportion to the test temperature. The change in the Seebeck coefficient from positive to negative values can be ascribed to a change of the diffusion direction of the carriers. In general, the formation of the second phase in the thermoelectric materials will introduce the barrier, which will block the low-energy carriers and thus, cause the decrease of the Seebeck coefficient $[44,45]$. In the high test-temperature range, the $\mathrm{Y}_{0.05}$-HEA shows the greatest absolute Seebeck coefficient. Nevertheless, with the formation of the Laves phase in $\mathrm{Gd}_{x} \mathrm{CoCrFeNiCu}$ alloys, the absolute $\mathrm{S}$ values decrease. We believe that it is because the rare earth element, Gd, possesses a special [46,47] electronic structure. Moreover, due to the bipolar conduction, the Seebeck coefficient is basically in direct proportion to the temperature, since noticeable minority carriers would be excited at high temperatures [21]. We therefore believe that it is necessary to combine both the composition and phase structure with band structures in order to obtain a satisfactory Seebeck coefficient. Serious efforts should be directed towards the band-structure engineering to make the HEAs as effective TE materials. Nowadays, typically investigated TE materials may be semiconducting oxides such as $\mathrm{ZnO}$ and $\mathrm{Bi}_{2} \mathrm{O}_{2} \mathrm{Se}[48,49]$. They exhibit $\mathrm{ZT}$ values of 0.025 and 0.047 at elevated temperatures of 1073 and $773 \mathrm{~K}$, respectively. Compared to that, the ZT of the HEA studied in the present manuscript is lower. However, high-entropy alloys are not traditional thermoelectric materials. The significance of this paper is to provide an exploration of the possibility of the high-entropy alloy as the thermoelectric material. It is found that the structure of HEA could be changed by doping elements and heat treatment to improve the thermoelectric properties, which provides guiding significance for the study of thermoelectric properties of high-entropy alloys. This is an important insight useful in establishing strategies aimed to design a new kind of thermoelectric materials.

\section{Conclusions}

We show the potential for the HEAs to act as thermoelectric materials even in the high temperature range. Moreover, it is found that the investigated $\mathrm{Al}_{0.3} \mathrm{CoCrFeNi}$ reaches a $\mathrm{ZT}$ value of 0.008 . There is 
a large variety of properties that could be discovered in the HEAs. There is a potential for the HEAs to attain an intrinsically-low lattice thermal conductivity due to the complex microstructure. Our research is a step toward the connection between the phase and band structure with the thermoelectric performance.

Author Contributions: W.D. performed the data analyses and wrote the manuscript; Z.Z. helped perform the analysis with constructive discussions; L.Z. and M.Z. helped document retrieval; L.P.K. and R.L. performed the manuscript review; G.L. contributed to the conception of the study.

Acknowledgments: The present work was supported by the Basic Research Project in the Hebei Province (Grant No. A2016203382), and the National Science Foundation of China (Grant No. 11674274). Pengfei Yu acknowledges the National Natural Science Funds of China (Grant No. 51601166). P.K.Liaw very much appreciates the support of National Science Foundation (DMR 1611180 and 1809640) and Army Office Project (W911NF-13-1-0438).

Conflicts of Interest: The authors declare no conflicts of interest.

\section{References}

1. Yeh, J.W. Recent progress in high-entropy alloys. Eur. J. Control 2006, 31, 633-648. [CrossRef]

2. Yeh, J.W.; Chen, S.K.; Lin, S.J.; Gan, J.Y.; Chin, T.S.; Shun, T.T.; Tsau, C.H.; Chang, S.Y. Nanostructured high-Entropy alloys with multiple principal elements: Novel alloy design concepts and outcomes. Adv. Eng. Mater. 2004, 6, 299-303. [CrossRef]

3. Zhang, Y.; Zuo, T.T.; Tang, Z.; Gao, M.C.; Dahmen, K.A.; Liaw, P.K.; Lu, Z.P. Microstructures and properties of high-entropy alloys. Prog. Mater. Sci. 2014, 61, 1-93. [CrossRef]

4. Chen, M.R.; Lin, S.J.; Yeh, J.W.; Chuang, M.H.; Chen, S.K.; Huang, Y.S. Effect of vanadium addition on the microstructure, hardness, and wear resistance of Al0.5CoCrCuFeNi high-entropy alloy. Metall. Mater. Trans. A 2006, 37, 1363-1369. [CrossRef]

5. Huang, P.K.; Yeh, J.W.; Shun, T.; Chen, S.K. Multi-principal-element alloys with improved oxidation and wear resistance for thermal spray coating. Adv. Eng. Mater. 2004, 6, 74-78. [CrossRef]

6. Poulia, A.; Georgatis, E.; Lekatou, A.; Karantzalis, A.E. Microstructure and wear behavior of a refractory high entropy alloy. Int. J. Refract. Met. Hard Mater. 2016, 57, 50-63. [CrossRef]

7. Zhang, K.B.; Fu, Z.Y.; Zhang, J.Y.; Shi, J.; Wang, W.M.; Wang, H.; Wang, Y.C.; Zhang, Q.J. Annealing on the structure and properties evolution of the CoCrFeNiCuAl high-entropy alloy. J. Alloys Compd. 2010, 502, 295-299. [CrossRef]

8. Gludovatz, B.; Hohenwarter, A.; Catoor, D. A fracture-resistant high-entropy alloy for cryogenic applications. J. Sci. 2014, 345, 1153. [CrossRef] [PubMed]

9. Hemphill, M.A.; Yuan, T.; Wang, G.Y. Fatigue behavior of $\mathrm{Al}_{0.5} \mathrm{CoCrCuFeNi}$ high entropy alloys. J. Acta Mater. 2012, 60, 5723-5734. [CrossRef]

10. Tang, Z.; Yuan, T.; Tsai, C.W. Fatigue behavior of a wrought $\mathrm{Al}_{0.5} \mathrm{CoCrCuFeNi}$ two-phase high-entropy alloy. J. Acta Mater. 2015, 99, 247-258. [CrossRef]

11. Shi, Y.; Yang, B.; Liaw, P.K. Corrosion-Resistant High-Entropy Alloys: A Review. J. Met. Open Access Metall. J. 2017, 7, 43. [CrossRef]

12. Shi, Y.; Yang, B.; Xie, X. Corrosion of $\mathrm{Al}_{\mathrm{x}} \mathrm{CoCrFeNi}$ high-entropy alloys: Al-content and potential scan-rate dependent pitting behavior. J. Corros. Sci. 2017, 119, 33-45. [CrossRef]

13. Seifi, M.; Li, D.; Yong, Z. Fracture Toughness and Fatigue Crack Growth Behavior of As-Cast High-Entropy Alloys. J. Mater. 2015, 67, 2288-2295. [CrossRef]

14. Miracle, D.B.; Senkov, O.N. A critical review of high entropy alloys and related concepts. J. Acta Mater. 2017, 122, 448-511. [CrossRef]

15. Song, H.; Tian, F.; Hu, Q.M. Local lattice distortion in high-entropy alloys. J. Phys. Rev. Mater. $2017,1,2$. [CrossRef]

16. Graus, W.H.J.; Voogt, M.; Worrell, E. International comparison of energy efficiency of fossil power generation. J. Energy Policy 2007, 35, 3936-3951. [CrossRef]

17. Wu, D.; Zhao, L.D.; Tong, X.; Li, W.; Wu, L.Q.; Pei, T.Y.; Huang, L.; Li, J.F.; Zhu, Y. Superior thermoelectric performance in $\mathrm{PbTe}-\mathrm{PbS}$ pseudo-binary: Extremely low thermal conductivity and modulated carrier concentration. Energy Environ. Sci. 2015, 8, 2056-2068. [CrossRef] 
18. He, J.; Kanatzidis, M.G.; Dravid, V.P. High performance bulk thermoelectrics via a panoscopic approach. Mater. Today 2013, 16, 166-176. [CrossRef]

19. Wu, H.; Zheng, F.; Wu, D.; Ge, Z.H.; Liu, X.; He, J. Advanced electron microscopy for thermoelectric materials. Nano Energy 2015, 13, 626-650. [CrossRef]

20. Nolas, G.S.; Sharp, J.; Goldsmid, H. Thermoelectrics: Basic Principles and New Materials Developments; Springer: New York, NY, USA, 2001.

21. Tritt, T.M. Recent trends in thermoelectric materials research. J. Chem. Phys. Carbon 2000, 31, 171-268.

22. Goldsmid, H.J. Recent Studies of Bismuth Telluride and Its Alloys. J. Appl. Phys. 1961, 32, $2198-2202$. [CrossRef]

23. Zhang, L.J.; Jiang, Z.K.; Zhang, M.D.; Fan, J.T.; Liu, D.J.; Yu, P.F.; Li, G.; Liu, R.P. Effect of solid carburization on the surface microsturcture and mechanical properties of the equiatomic CoCrFeNi high-entropy alloy. J. Alloys Compd. 2018, 769, 27-36. [CrossRef]

24. Wu, H.J.; Zhao, L.D.; Zheng, F.S.; Wu, D.; Pei, Y.L.; Tong, X.; Kanatzidis, M.G.; He, J.Q. Broad temperature plateau for thermoelectric figure of merit $\mathrm{ZT}>2$ in phase-separated $\mathrm{PbTe}_{0.7} \mathrm{~S}_{0.3}$. Nat. Commun. 2014, 5, 4515. [CrossRef] [PubMed]

25. Li, Y.; Li, F.; Dong, J.; Ge, Z.; Kang, F.; He, J.; Du, H.; Li, B.; Li, J.F. Enhanced mid-temperature thermoelectric performance of textured SnSe polycrystals made of solvothermally synthesized powders. J. Mater. Chem. C 2016, 4, 2047-2055. [CrossRef]

26. Zhang, M.D.; Zhang, L.J.; Fan, J.T.; Li, G.; Liaw, P.K.; Liu, R.P. Microstructure and enhanced mechanical behavior of the $\mathrm{Al}_{7} \mathrm{Co}_{24} \mathrm{Cr}_{21} \mathrm{Fe}_{24} \mathrm{Ni}_{24}$ high-entropy alloy system by tuning the $\mathrm{Cr}$ content. Mater. Sci. Eng. A 2018, 733, 299-306. [CrossRef]

27. Mahan, G.; Sales, B.; Sharp, J. Thermoelectric Materials: New approaches to an old problem. Phys. Today 1997, 50, 42-47. [CrossRef]

28. Cui, P.; Ma, Y.M.; Zhang, L.J.; Zhang, M.D.; Fan, J.T.; Dong, W.Q.; Yu, P.F.; Li, G. Microstructure and mechanical behaviors of $\mathrm{CoFeNiMnTi} \mathrm{Al}_{1-\mathrm{x}}$ high entropy alloys. Mater. Sci. Eng. A 2018, 731, 124-130. [CrossRef]

29. Wu, D.; Zhao, L.D.; Zheng, F.; Jin, L.; Kanatzidis, M.G.; He, J. Understanding nanostructuring processes in thermoelectrics and their effects on lattice thermal conductivity. Adv. Mater. 2016, 28, 1410-1436. [CrossRef] [PubMed]

30. Snyder, G.J.; Toberer, E.S. Complex thermoelectric materials. Nat. Mater. 2008, 7, 105. [CrossRef] [PubMed]

31. Yamini, S.A.; Mitchell, D.R.G.; Wang, H.; Gibbs, Z.M.; Pei, Y.; Dou, S.X.; Snyder, G.J. Origin of resistivity anomaly in p-type leads chalcogenide multiphase compounds. AIP Adv. 2016, 5, 66.

32. Takagiwa, Y.; Pei, Y.; Pomrehn, G.; Snyder, G.J. Dopants effect on the band structure of PbTe thermoelectric material. Appl. Phys. Lett. 2010, 101, 105. [CrossRef]

33. Fan, J.T.; Zhang, L.J.; Yu, P.F.; Zhang, M.D.; Liu, D.J.; Cui, P.; Zhou, Z.; Ma, M.Z.; Jing, Q.; Li, G.; et al. Improved the microstructure and mechanical properties of AlFeCoNi high-entropy alloy by carbon addition. Mater. Sci. Eng. A 2018, 728, 30-39. [CrossRef]

34. Heremans, J.P.; Jovovic, V.; Toberer, E.S.; Saramat, A.; Kurosaki, K.; Charoenphakdee, A.; Yamanaka, S.; Snyder, G.J. Enhancement of thermoelectric efficiency in PbTe by distortion of the electronic density of states. Science 2008, 321, 554-557. [CrossRef] [PubMed]

35. Pei, Y.; Shi, X.; Lalonde, A.; Wang, H.; Chen, L.; Snyder, G.J. Convergence of electronic bands for high performance bulk thermoelectrics. Nature 2011, 473, 66. [CrossRef] [PubMed]

36. Shafeie, S.; Guo, S.; Hu, Q.; Fahlquist, H.; Erhart, P.; Palmqvist, A. High-entropy alloys as high-temperature thermoelectric materials. J. Appl. Phys. 2015, 118, 105-144. [CrossRef]

37. Zhang, L.J.; Fan, J.T.; Liu, D.J.; Zhang, M.D.; Yu, P.F.; Jing, Q.; Ma, M.Z.; Liaw, P.K.; Li, G.; Liu, R.P. Effects of rar element, Y, additions on the microstructure and mechanical properties of CoCrFeNi high entropy alloy. Mater. Sci. Eng. A 2018, 725, 437-446. [CrossRef]

38. Wang, W.R.; Wang, W.L.; Yeh, J.W. Phases, microstructure and mechanical properties of $\mathrm{Al}_{\mathrm{x}} \mathrm{CoCrFeNi}$ high-entropy alloys at elevated temperatures. J. Alloys Compd. 2014, 589, 143-152. [CrossRef]

39. Hicks, L.D.; Harman, T.C.; Sun, X.; Dresselhaus, M.S. Experimental study of the effect of quantum-well structures on the thermoelectric figure of merit. Phys. Rev. B Condens. Matter 2002, 53, 450-453.

40. Venkatasubramanian, R.; Silvola, E.; Colpitts, T.; O'Quinn, B. Thin-film thermoelectric devices with high room-temperature figures of merit. Nature 2001, 413, 597-602. [CrossRef] [PubMed] 
41. Dresselhaus, M.S.; Chen, G.; Tang, M.Y.; Yang, R.; Lee, H.; Wang, D.; Ren, Z.; Fleurial, J.P.; Gogna, P. New Directions for Low-Dimensional Thermoelectric Materials. Adv. Mater. 2007, 38, 1043-1053. [CrossRef]

42. Liu, D.J.; Yu, P.F.; Liaw, P.K.; Li, G.; Liu, R.P. High-temperature high-entropy alloys $\mathrm{Al}_{\mathrm{x}} \mathrm{Co}_{15} \mathrm{Cr}_{15} \mathrm{Ni}_{70-\mathrm{x}}$ based on the Al-Ni binary system. Mater. Sci. Eng. A 2018, 724, 283-288. [CrossRef]

43. Zhang, L.J.; Fan, J.T.; Liu, D.J.; Zhang, M.D.; Yu, P.F.; Jing, Q.; Ma, M.Z.; Liaw, P.K.; Li, G.; Liu, R.P. The microstructural evolution and hardness of the equiatomic CoCrCuFeNi high-entropy alloy in the semi-solid state. J. Alloys Compd. 2018, 745, 75-83. [CrossRef]

44. Zheng, Y.; Wang, S.; Liu, W.; Yin, Z.; Li, H.; Tang, X.; Uher, C. Thermoelectric transport properties of p-type silver-doped $\mathrm{PbS}$ with in situ $\mathrm{Ag}_{2} \mathrm{~S}$ nanoprecipitates. J. Phys. D Appl. Phys. 2014, 47, 323-328. [CrossRef]

45. Tan, Q.; Zhao, L.D.; Li, J.F.; Wu, C.F.; Wei, T.R.; Xing, Z.B.; Kanatzidis, M.G. Thermoelectrics with earth abundant elements: Low thermal conductivity and high thermopower in doped SnS. J. Mater. Chem. A 2014, 2, 17302-17306. [CrossRef]

46. Yan, M.F.; Liu, Z.R.; Bell, T. Effect of Rare Earths on Diffusion Coefficient and Transfer Coefficient of Carbon during Carburizing. J. Rare Earths 2001, 19, 122-124.

47. Yuan, Z.X.; Yu, Z.S.; Tan, P. Effect of rare earths on the carburization of steel. J. Mater. Sci. Eng. A 1999, 267, 162-166. [CrossRef]

48. Zhan, B.; Butt, S.; Liu, Y. High-temperature thermoelectric behaviors of Sn-doped n-type $\mathrm{Bi}_{2} \mathrm{O}_{2}$ Se ceramics. J. Electroceram. 2015, 34, 175-179. [CrossRef]

49. Tsubota, T.; Ohtaki, M.; Eguchi, K. Thermoelectric properties of Al-doped ZnO as a promising oxide material for high-temperature thermoelectric conversion. J. Mater. Chem. 1997, 7, 85-90. [CrossRef]

(C) 2018 by the authors. Licensee MDPI, Basel, Switzerland. This article is an open access article distributed under the terms and conditions of the Creative Commons Attribution (CC BY) license (http:/ / creativecommons.org/licenses/by/4.0/). 